\title{
ANÁLISE QUALITATIVA DE JOGOS DE TABULEIRO VISANDO AUXILIAR NA CRIAÇÃO DE UM FRAMEWORK PARA A VERSÃO DIGITAL DE UM JOGO VOLTADO À EDUCAÇÃO PATRIMONIAL
}

\author{
Flávio Barbosa da Silva/UFPE \\ Solange Galvão Coutinho (orientadora)/UFPE \\ Eva Rolim Miranda (coorientadora)/UFAL
}

\section{RESUMO}

Este artigo apresenta os resultados de um estudo para as definições de parâmetros a serem aplicados no desenvolvimento da estrutura editável de um jogo digital, objeto de pesquisa de doutorado. Busca explorar a utilização de um artefato gráfico digital como uma estratégia participativa de educar para a preservação cultural. A pesquisa prevê a realização de um estudo de campo com desenvolvimento e teste de um framework ${ }^{1}$ editável do Jogo do Patrimônio Digital Versão Beta ${ }^{2}$. Durante o refinamento da metodologia foi necessário conhecer mais esse universo e encontrar características a serem aplicadas na nova versão. Para tanto, foi realizada uma análise qualitativa de 25 jogos de tabuleiro (14 em versões digitais). Resultados apontam que produzir jogos envolve, para além da técnica, a produção de narrativas.

Palavras-chave: Análise qualitativa; Educação; Framework; Design da Informação; Jogo.

\section{Introdução}

As formas de comunicar e educar sempre estiveram em processo de modificação, e, dentre as muitas alterações ocorridas nos últimos anos, emerge a busca por soluções para resolver novos problemas, especialmente os dedicados à educação de forma não restritiva. A pandemia de Covid-19, impôs o fechamento de escolas em todo o mundo, afetando milhões de estudantes e estimulando a educação remota em todos os níveis.

Surgiram novos desafios a serem superados no processo de ensino-aprendizagem, especialmente no trabalho dos docentes, que precisaram adaptar suas metodologias neste contexto (AGUIAR, 2020). Nesse sentido, dentre os meios utilizados para se promover o aprendizado, existem aqueles que apostam na ludicidade como forma de facilitar a interação com o conteúdo, o que inclui a gamificação ${ }^{3}$, e a utilização e/ou produção de jogos. No ambiente virtual, a necessidade de utilização deste tipo de ferramenta didática tem se mostrado relevante para melhorar a interação e o engajamento entre docentes e discentes.

Gomes e Batista (2014) evidenciam ganhos de aprendizagem, desenvolvimento da autonomia e criatividade quando jogos são desenvolvidos com os estudantes durante as aulas e defendem que para além do uso de jogos digitais nas escolas, também se explore o desenvolvimento de jogos por alunos 
como estratégia de aprendizagem. O jogo é um agente facilitador no processo de aquisição de conhecimento e por sua característica de dinamismo, exige um grande cuidado no seu planejamento e execução (VASCONCELOS, et al., 2012).

O desenvolvimento de jogos digitais (game design) é uma ação complexa e envolve conhecimentos específicos e equipes multidisciplinares, a produção começa com a definição do seu conceito inicial e termina com a criação de uma versão final do jogo, mas várias etapas (especificamente quatro, sendo: análise de similares, geração de alternativas, prototipagem e testagem) acontecem entre esses dois pontos (CHANDLER, 2012). Embora existam diferentes tipos de jogos, este trabalho objetiva investigar, no contexto nacional, o game design de jogos de tabuleiro modernos ${ }^{4}$, produzidos em suportes analógicos ou digitais.

\section{Método}

O procedimento utilizado para seleção da amostra foi não probabilístico por conveniência (GIL, 2008), este método de seleção nos permite uma amostra, de acordo com a facilidade de acesso, no nosso caso, a busca entre os jogos disponíveis no acervo pessoal, de familiares e de amigos. Dos jogos existentes nos acervos, buscou-se identificar aqueles jogados em duas plataformas digitais gratuitas (Board Games Arena - BGA e Steam). A pesquisa se deu por meio de observação e da prática de jogatinas presenciais e online, interagindo com até quatro jogadores/as experientes para além do pesquisador, durante dezesseis encontros de janeiro a junho de 2021.

Foram realizados registros escritos e fotográficos, e, os dados coletados foram organizados em uma planilha eletrônica online. Foram levantados e testados 25 jogos de tabuleiro, sendo que 11 apresentam apenas o formato analógico e 14 já apresentam também formatos digitais. Todos os jogos mapeados são destinados à adolescentes e jovens, e, quanto à concepção de aprendizagem, se caracterizam como instrumentos lúdicos voltados prioritariamente para a diversão, não voltado diretamente para atividades educativas, podendo ser utilizados como estratégias paradidáticas.

Os critérios observados ${ }^{5}$ foram adaptados a partir dos propostos por Ribeiro e Coscarelli (2009) para análise da qualidade de jogos online de finalidade didática, mas que são úteis e aplicáveis à análise de jogos de outras formas e com quaisquer outros propósitos: tema; objetivos; jogabilidade; componentes; quantidade de jogadores/as por partida; tempo de partida; estratégias; dinâmica; mecânicas; recompensas e, se continham ou não algum tipo de scoreboard ou leaderboard ${ }^{6}$. Visando ampliar o universo de informações sobre os jogos de tabuleiro, também foram visitadas duas grandes relevantes plataformas on-line sobre os boardgames: a plataforma Ludopedia de caráter nacional, e 
uma mundial denominada por Board Game Geek, as quais possibilitaram a coleta de informações sobre as impressões de outros usuários sobre os jogos desta análise.

\section{Discussão}

Dentre os jogos observados, a utilização de temáticas bem definidas foi uma característica em geral, a maioria ( $n=18 / 25$ ) se relaciona com história e/ou cultura e trazem enredos sobre fatos históricos, civilizações, sistemas produtivos, econômicos e sociais. Os objetivos, as estratégias e dinâmicas estão sempre associados às narrativas. Em nove jogos $(n=9 / 25)$, os objetivos são de explorar algum lugar ou caminho e colecionar itens. Oito $(n=8 / 25)$, objetivavam construir algo, e quatro $(n=4 / 25)$ tinham como objetivo produzir ou cultivar algo, os demais apresentam objetivos distintos: negociar, desvendar incógnitas, contratar artistas e prender um bandido.

Durante a análise foi possível observar grande quantidade e a variedade de componentes (peças) que constituem cada jogo. A pluralidade de formatos e o cuidado que foi dedicado à criação e a confecção dessas peças impressionam, principalmente nas versões físicas. Foram encontradas peças muito bemacabadas, e que por muitas vezes podem ser combinadas de diversas formas (Figura 1). Os componentes mais recorrentes são: uma base, como o próprio tabuleiro, cartas e dados, mas também é possível encontrar meeples (pinos para o jogo), taios (peças para compor o tabuleiro). O jogo com menos peças contém apenas 70 (setenta), o que tem mais, passa de 600 (seiscentas).
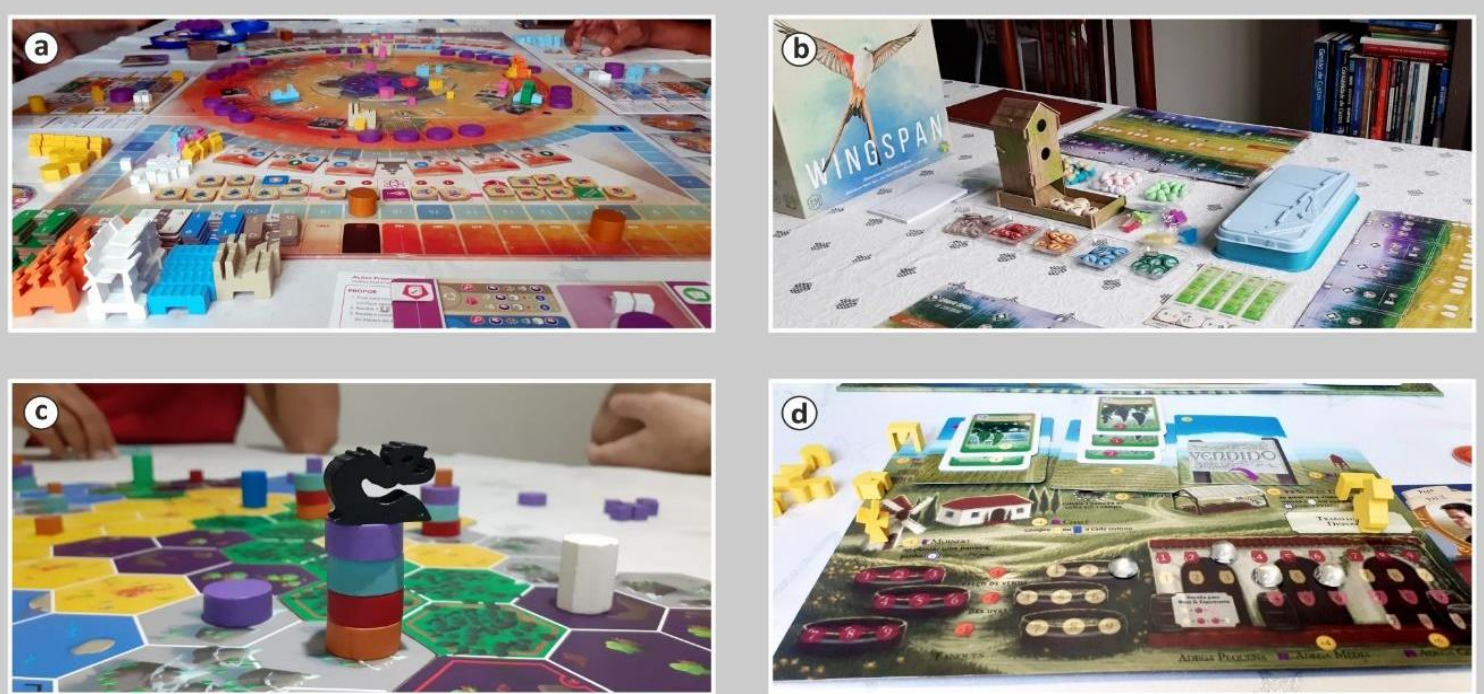

a) Peças e tabuleiro do jogo $\mathrm{CO}^{2}$ Segunda Chance (estruturas de geração de energia)

b) Peças do jogo Wingspan (viveiro, ovos coloridos, tabuleiros individuais...)

c) Detalhe das peças e tabuleiro do jogo Cryptid (local onde o monstro foi encontrado)

d) Peças e tabuleiro individual do jogo Viticulture (Moinho, parreiral, adega...)

Figura 1. Composição com fotos de jogos com peças que se destacam pela qualidade. Fonte: Flávio Barbosa da Silva. Elaborado pelo autor, 2021 
Os jogos apresentam estratégias para aprimorar a jogabilidade e para estimular a rejogabilidade (ou seja, melhorar a experiência do usuário, estimulando que a pessoa jogue novamente). Dentre essas, está a apresentação de tabuleiros que se complementam com cartas e/ou com peças como taios, o que proporciona maior interação e experiências diferentes em cada partida. Um exemplo disso pode ser percebido no jogo Cryptid (Figura 1, item c) que mesmo tendo uma pequena quantidade de elementos, possibilita diferentes formas de montar o tabuleiro e de interação com o jogo. $O$ tabuleiro é modulável, composto por seis conjuntos de campos hexagonais, e permite muitas formas de montagem. O objetivo é encontrar um monstro, e a cada partida ele poderá ser encontrado em um campo diferente.

O tempo de montagem/carregamento do tabuleiro, também interfere na experiência do usuário, destacando-se aqueles que oferecem menor tempo de montagem quando em formato analógico, e menor tempo de carregamento quando em formato digital, ressalvando-se que a velocidade de conexão à internet também pode influir nesta experiência. Ainda sobre a duração das partidas, a maioria dos jogos ( $n=13 / 25$ ) demandam tempo máximo de 60 minutos. Os jogos mais complexos são mais demorados, de forma que nestes casos, jogar em plataformas digitais, reduz o tempo total de jogo visto que não se precisa montar o setup (ambiente do jogo).

Nas plataformas Ludopedia e Board Game Geek foi possível observar algumas características importantes: os jogos são divididos em duas grandes categorias: família e estratégia, sendo que alguns podem estar inseridos nas duas ao mesmo tempo. Além disso, é possível classificá-los quanto ao seu peso (nível de complexidade), expressado entre os números de 1 a 5 , sendo o nível 5 o mais elevado. O infográfico dos jogos analisados (Figura 2) traz essa informação em barras que indicam os níveis das complexidades. Os jogos são avaliados pelos usuários gerando um ranking geral e dentro da sua classificação. As plataformas são editadas pelos/as jogadores/as cadastrados, de forma participativa e gratuita, e, além de informações sobre os jogos, ainda possuem contribuições de jogadores/as mais experientes quanto a melhorias e ajudas, além de desenvolverem versões alternativas. 


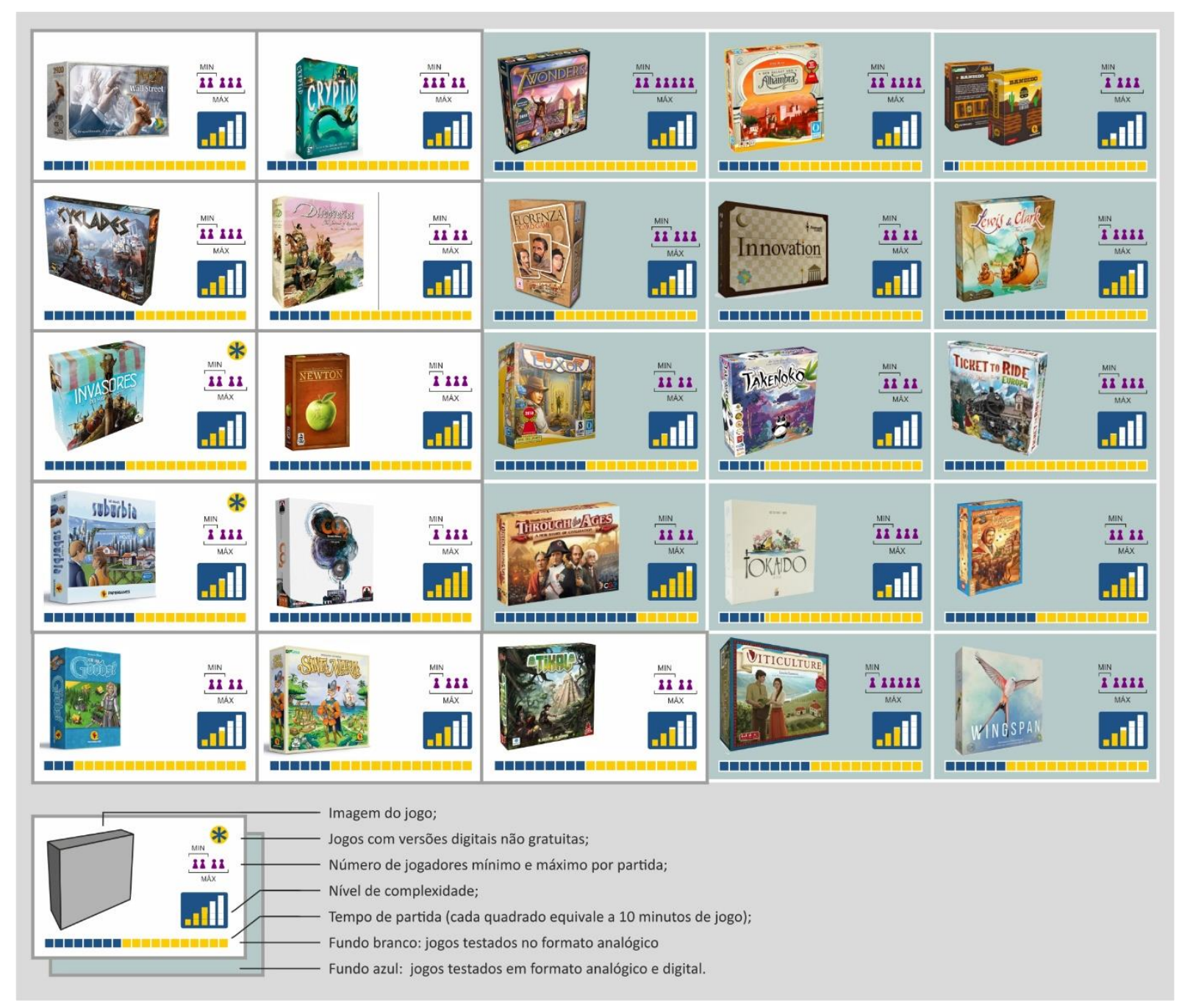

Figura 2. Infográfico dos jogos analisados.

Fonte: Flávio Barbosa da Silva. Elaborado pelo autor, 2021

Um mesmo jogo pode ter algumas diferenças entre suas versões analógica e digital, mantendo-se tema e objetivo, mas às vezes com a aplicação de alguma estratégia ou mecânica diferente, visando o ajuste de plataforma, ou ainda o estímulo à rejogabilidade. Um exemplo se dá no jogo Takenoko, que foi observado nas duas versões (física e digital). Embora seja um jogo bem avaliado (tanto globalmente quanto em seu nicho), com a atribuição de notas por precisamente 36.568 pessoas no site Board Games Geek, apresentou dois problemas para muitos usuários: baixa interação dos jogadores/as e o uso de cores que dificultavam a ação de jogadores daltônicos. O designer do jogo propôs melhorias para esses problemas sugerindo algumas mudanças nas regras, bem como alterações no layout (figura 3, item d). Além das melhorias nas mecânicas e do tabuleiro, para além da interação competitiva, recentemente o autor incluiu uma variante cooperativa onde as pessoas podem baixar as regras e tabuleiro gratuitamente. O Takenoko ainda não incorporou na sua versão analógica as melhorias 
sugeridas (figura 3, item a), mas é possível jogá-lo na nova versão escolhendo esta opção na plataforma Board Games Arena experimentada (figura 3, item c).

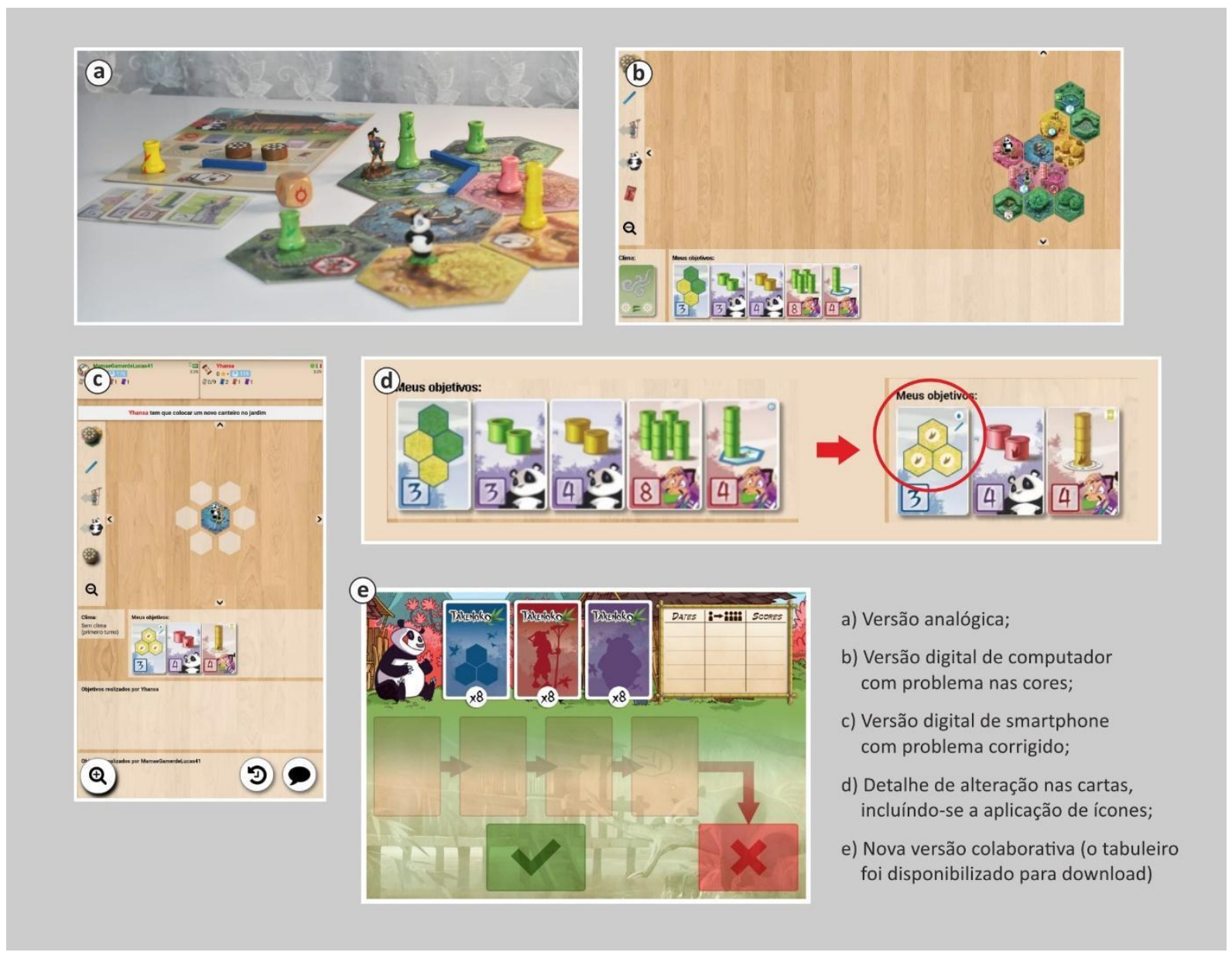

Figura 3. Composição de imagens demonstrando as alterações nas versões do jogo Takenoko.

Fonte: Flávio Barbosa da Silva. Elaborado pelo autor, 2021

Dos 25 jogos, apenas sete $(n=7 / 25)$ apresentaram a possibilidade de jogo solo. E a maioria dos jogos ( $n=14 / 25$ ) são formatados para partidas de dois a quatro jogadores/as. Dez ( $n=10 / 25)$ jogos podem ser praticados por cinco ou mais jogadores/as. Os tipos de interação mais recorrentes são as jogadas sequenciais e competitivas. Apenas o jogo 7 Wonders $(n=1 / 25)$ tem sua forma de jogada simultânea. Também se percebeu que algumas mecânicas direcionam para a colaboração entre os/as jogadores/as. O Jogo Bandido $(n=1 / 25)$ só apresenta versão colaborativa (em que todos os/as jogadores/as buscam um objetivo comum), dois jogos $(n=2 / 25)$, sendo o $\mathrm{CO}^{2}$ Segunda Chance, e Takenoko apresentam versões competitivas e colaborativas.

Todos os jogos têm alguma forma de scoreboard/leaderboard (Figura 4). Nas versões físicas, em alguns casos isso já está intrínseco no tabuleiro, e, outros são tabuleiros de pontuação à parte. $\mathrm{O}$ tabuleiro de pontuação ainda é tradicionalmente muito utilizado, e foi percebido em vinte ( $n=20 / 25)$ jogos (seja no 
próprio tabuleiro do jogo ou à parte). Desses, foram percebidas novas formas de scores (pontuação) e de vitória, uma dessas formas é realizar conquistas, ou a formação de coleções o que foi percebido em sete jogos $(n=7 / 25)$. Outros cinco $(n=5 / 25)$, sendo: Bandido, Cryptid, Cyclades, Innovation e Lewis e Clark são exemplos de jogos que não apresentam formas de pontuação, e a vitória é alcançada por meio da conclusão de algum objetivo. Além da diferença de apresentação, também ficou claro que existiam diferentes formas de lidar com a pontuação.

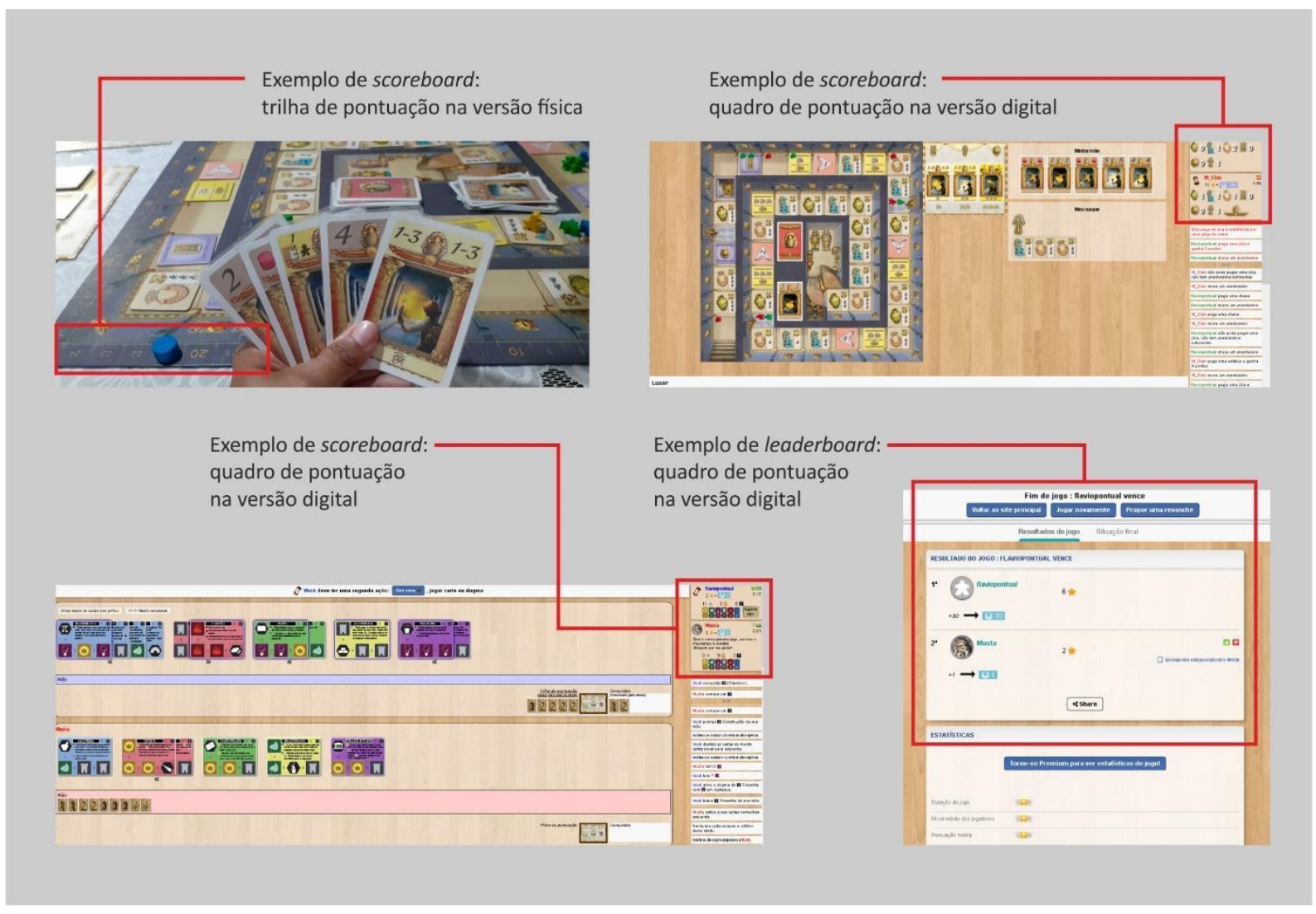

Figura 4. Composição de imagens demonstrando as scoreborard e leaderboard. Fonte: Flávio Barbosa da Silva. Elaborado pelo autor, 2021

\section{Considerações Finais}

Esta análise de similares revelou direcionamentos para melhorar definição dos parâmetros de criação e de balanceamento dessa nova versão do Jogo do Patrimônio, e esclareceu que o jogo, nos formatos analógico e digital, pode contar com uma base e oferecer expansões, e isso ocorre tanto para proporcionar mais rejogabilidade como para resolver problemas que foram identificados pelos usuários. Os jogos de tabuleiro modernos apresentam regras e mecânicas que exigem dos/das jogadores/as mais do que sorte para avanço no tabuleiro, solicita o estabelecimento de estratégias para a vitória. 
Os enredos e as mecânicas que envolvem os jogos de tabuleiro contribuem para o processo de criação, abrangendo uma parte do trabalho relacionada com a narrativa e outra com a técnica do desenvolvimento do framework. O número ideal de jogadores/as deve ser de dois a quatro (jogadores/as ou grupos, se for o caso de aplicação em grupos). Este foi o recorte mais recorrente e provavelmente ocorreu porque jogos de modo solo normalmente envolvem mecânicas diferentes, e a realização de partidas com muitos participantes também pode interferir na mecânica, bem como pode dificultar a mobilização de pessoas para compor a partida.

A quantidade de jogadores/as e o tempo de partida constituíram variáveis importantes nos jogos em seu formato digital, uma vez que jogos analógicos podem ser sinônimos de demora (especialmente pela montagem e desmontagem do setup em jogos que tenham muitas peças). $\mathrm{O}$ formato digital permite que o tempo que seria gasto na preparação de jogos mais demorados possa ser realocado para conhecer outros jogos. Outra vantagem está em poder experimentar a versão com mais competidores, isso porque nem sempre é possível conseguir mobilizar várias pessoas para jogar presencialmente, principalmente no cenário pandêmico.

Os jogos digitais tiveram seu início na década de 1970, e imperiosamente inspiraram-se nos modelos lúdicos então existentes. Com a evolução da tecnologia, esses jogos se tornaram mais inovadores, contudo ainda se preserva a sinergia entre jogos de tabuleiro e jogos digitais. Inúmeros jogos de tabuleiro foram implementados em versões digitais, sendo muito provável que os jogos digitais tenham também influenciado na criação dos jogos de tabuleiro modernos (DUARTE, 2012). Com observação aos resultados desta análise, percebe-se a relevância de que no desenvolvimento de jogos, (ou neste caso, de um framework), independentemente do tipo de suporte, seja analógico ou digital, a busca de referências pode ocorrer de forma ampla e irrestrita. Por fim, um estudo futuro para observação do engajamento de jogadores/as, pode revelar se os parâmetros estão precisamente ajustados para o público-alvo.

\section{Referências}

AGUIAR, Felipe Rodrigues Magalhães de. Pandemia da covid-19 e demandas de atuação docente. Revista Diálogos Acadêmicos, v. 9, n. 1, 2020.

BORGES, Simone de Souza; DURELLI, Vinícius. H. S; REIS, Helena Macedo; ISOTANI, Seiji. A systematic mapping on gamification applied to education. Proceedings of the 29th ACM Symposium on Applied Computing, 2014, p. 216-222.

CHANDLER, Heather Maxwell. Manual de produção de jogos digitais. Tradução: Aldir José Coelho Corrêa da Silva. 2a ed. Porto Alegre: Bookman, 2012.

DUARTE, Luis Cláudio S. Jogos de Tabuleiro no Design de Jogos Digitais. Proceedings of SBGames 2012, p. 132-137. 
GIL, Antonio Carlos. Métodos e Técnicas de Pesquisa Social. 6. ed. São Paulo: Editora Atlas, 2008.

RIBEIRO, Andréa L.; COSCARELLI, Carla V. Jogos online para alfabetização: o que a internet oferece hoje. Anais eletrônicos do 3 Encontro Nacional sobre Hipertexto, Belo Horizonte, 2009. Belo Horizonte: CEFET-MG, 2009.

VASCONCELOS, Elaine da Silva; ROCHA, Ithiara Fernandes; SILVA, Jaqueline Patrício da; CEZAR, Katiusca Lima; SOARES, Paulenice de Sousa; MOREIRA, Thamires dos Santos; LORENZO, Jorge Gonçalo Fernandez; SANTOS, Márcia de Lourdes Bezerra dos. Jogos: uma forma lúdica de ensinar. VII CONNEPI Congresso Norte Nordeste de Pesquisa e Inovação. Palmas. 2012.

\footnotetext{
${ }^{1}$ Estrutura de um conjunto de técnicas para desenvolver algo.

${ }^{2}$ Versão eletrônica de um jogo de tabuleiro já existente, criado como ferramenta de educação patrimonial. A primeira versão foi criada por uma equipe da FUNDARPE, e, depois foram criadas versões participativas, estudadas no mestrado de Flavio Barbosa (2018).

${ }^{3}$ Conjunto de mecanismos de regras, objetivos e resultados, que vem sendo amplamente utilizado nos últimos anos, no contexto educacional, como forma de melhorar o engajamento (BORGES, et al. 2014).

${ }^{4}$ Se diferenciam dos tradicionais pela utilização de mecânicas que aumentam a necessidade de estratégias para além da sorte, o entretenimento e a rejogabilidade.

5 Tema: o jogo pode estar relacionado com algum contexto de ensino em sala de aula ou o repertório refere-se a um conteúdo em que pode haver um contexto, sejam fatos históricos, nomes de países...; Objetivos: aquilo que se espera ser desempenhado pelos jogadores/as, desde produzir ou colecionar itens; Jogabilidade: como se dá a experiência do jogador e como se estimula a jogar novamente. Precisa ser eficiente e sem falhas na execução e interação; Componentes: todos os jogos são compostos por muitos itens (peças) que podem inclusive ser adicionadas posteriormente; Quantidade de jogadores/as: alguns jogos podem ser jogados em modo solo (apenas um jogador), enquanto outros exigem haver oponentes; Tempo de partida: cada jogo tem um tempo aproximado pré-definido para acontecer e isso pode interferir na experiência do usuário; Estratégias e Dinâmicas são ações que estão relacionadas com as tarefas que precisam ser desenvolvidas para o avanço no jogo; Mecânica: descreve e padroniza os tipos de interação no jogo; Recompensas: relacionadas com a motivação do jogador, pode ser por pontos ou acúmulos de elementos, e ocorre de formas gradativas conforme desempenho;

${ }^{6}$ Scoreboard e Leaderboard são elementos específicos respectivamente para marcar a pontuação e para criar um ranking (painel de classificação) comparativo de resultados entre jogadores/as.
} 